\title{
UNDERSTANDING QUESTIONS AND AN- SWERS IN CONTEXT: AN ARGUMENT FOR MULTI-CHANNEL ANALYSIS
}

\author{
Dawn Archer, \\ Manchester Metropolitan University \\ d.archer@mmu.uk
}

\begin{abstract}
Currently, understanding what questions and answers mean in context equates to accounting for the questioner's role as well as what they expect to (versus) achieve, the position as well as form/function of their question(s) within the interaction: and, if spoken, their delivery, as well as whether a response is given, what type, how, etc. This paper advocates for a further widening of the linguistic analytical lens beyond traditional syntactic/ pragmatic criteria so that we might account, in turn, for participants' facial expressions, body movements and gestures as they deliver their questions and/or respond to others. The paper argues this is particularly pertinent when negotiating meaning generally and crucial when seeking to understand potentially deceptive and/or evasive moves on the part of participants.
\end{abstract}

Keywords: answer(s), elicitation, face(work), meaning-in-context, multichannel analysis, question(s)

\section{Introduction}

This paper analyses two authentic exchanges, with a specific focus on the questions and answers contained within them. The first relates to a 2011 US press interview given by Anthony Weiner, congressional representative for New York's ninth district, following allegations he had sexted a 21-year old (see especially Section 2). The second relates to a UK police interview given by (then) school caretaker, Ian Huntley, shortly after two ten-year-old girls from a nearby school - Holly Wells and Jessica Chapman - went missing (see especially Section 3). These exchanges were chosen for two reasons. First, they represent activity types that are known to make use of question-and- 
answer sequences (albeit in activity-specific ways). Second, they each contain elements of deception and/or evasion. Weiner denies inappropriate behaviour in the press interview we are focusing upon, for example, but in a later press conference (CBS 2011) admitted to having "exchanged messages and photos of an explicit nature with about six women" over a three-year period. His actions (and then lying about them) precipitated his resignation from Congress in June the same year. He has since served a prison sentence for additional sexting offences (this time with a minor). Huntley denies having contact with the ten-year-olds, Holly and Jessica, in the police interview discussed in this paper. He was formally charged with two counts of murder on $20^{\text {th }}$ August 2002, nonetheless. It later transpired (at his trial) that he had invited the girls into the house he shared with Maxine Carr, under the pretence she was inside (they seemingly agreed because of knowing Maxine). He is believed to have become physical with the girls shortly thereafter and, when they resisted, killed them. Although he thought he had covered his tracks by first hiding (and partially burning) their bodies, and then disposing of their clothes and possessions, he was ultimately convicted of their murders $\left(17^{\text {th }}\right.$ December 2003), and is currently serving a life sentence in a UK prison.

Choosing exchanges representative of activity types that are known to (1) make use of question-and-answer sequences, and (2) contain elements of deception and/or evasion means we can explore how the former can be used in an attempt to do the latter, and how we might therefore account for the latter when explaining how questions and answers (sometimes) work in such activity types. For example, police officers tend to use questions to glean information, query, accuse, etc., with the ultimate aim of testing the veracity of a witness's or suspect's account of events (see Vrij 2008, Collin 2020, this issue). It is thus understood that they have "the formal power...to set the interview agenda" (McKinley and McVittie 2009:176). Evidence of participants playing about with these normative expectations is somewhat limited, because of the difficulties associated with securing such datasets. Haworth (2006) nonetheless provides us with one such example, involving a (now notorious) doctor named Harold Shipman. He disrupted the interview process "right at the start", by signalling a need to "clarify something first" immediately after the police officer began setting "up the agenda for [their] interaction" following his delivery of "the mandatory caution" (ibid:739). News interviews are also generally described as having a well-established structure, such that "interviewers restrict themselves to questioning and interviewees restrict themselves to answering interviewer questions, or at least responding to them" (Clayman and Heritage 2002:97). Indeed, Konzett (2012:96) goes as far as to state that "stick[ing] to this rule" is "vital", "since an interview in which both parties are allowed to ask questions is no longer an interview". Clayman and Heritage (2002) go on to provide counter examples of politicians disrupting rather than playing what they call "the interview game" in various ways (by, e.g., asking questions of their own, attacking the questioner because of their questions, etc.). They still 
concur with Konzett's (2012) overall sentiment, though, as they describe these disruptions as rarities. They then draw upon them as a means of highlighting the various ways in which the "weighty" institutional framework serves to shape interviewers' and interviewees' "facework", by constraining "how the actions" of both can be "interpreted and treated" (Clayman and Heritage 2002:148) and, hence, what is deemed appropriate in facework terms. It is worth noting here, though, that the "parameters of the permissible" in this case include interviewers' "continuing with questioning that will appear reasonable to the general public" even when they "know privately" that the "interviewee is lying" (ibid). This means that, contra police officers, news interviewers can play "the interview game" in ways that condone lying when this suits their purpose (but see Section 2).

Following Goffman (1967:5), I recognise face to be the line an interlocutor claims based upon what s/he believes others are assuming about him or her; and facework to be the actions interlocutors engage in, and occasionally negotiate over, in order to make what they are doing consistent with that developing line. When Goffman discussed questions, he described them as a very controlling form of expression, for example. Indeed, they impact upon a target's negative face, that is, their "want" to act freely, without imposition (Brown and Levinson 1987) just by expecting an answer. In some contexts in particular, those with asymmetrical participant roles - they can also affect a target's positive face, that is, their "want" to be liked, appreciated, approved of, etc. (Brown and Levinson 1987). Penman (1994:30) provides the example of "Did you drink the entire bottle of scotch?" (asked in a courtroom), which "not only impos[ed] on the" target's "negative face by asking for factual information", but also" their "positive face by suggesting alcohol indulgence". As Penman (1994:31) goes on to explain, courtroom questions are not restricted to establishing "the facts of the matter" precisely because judicial decision-making (in an Anglo-American context at least) is about unearthing "the reasons" a defendant or witness behaved/spoke in a certain way. Questions, in such cases, thus provide barristers (in particular) with an important means of focusing the jury, judge, etc., on a target's demeanour under the veil of getting to "the facts of the matter" (Penman 1994:30-1).

As will become clear, the two press interviewers in the press exchange (see Section 2) and the police officer in the police interview (see Section 3) also sought to get to the facts of the matter. The former, moreover, engaged in a level of impression management (henceforth IM) as part of this, by designing their questioning sequences in such a way as to give the impression Weiner was being deliberately evasive for some reason. IM was initially conceptualised by Goffman $(1959: 17,22)$ to capture the process(es) by which people (attempt to) influence the perceptions of others (in relation to appearance, a person or persons, object, event, etc.). Such behaviour can be conscious - and hence strategic - or subconscious - and hence more akin to a learned behaviour. This paper will reveal that IM was primarily used for the former purpose by 
the two press officers and Weiner (see Section 2), as well as Huntley when answering a particularly loaded polar interrogative from the police officer ("was there any occasion that you actually came into contact physical contact with the girls?": see Section 3). That is, to strategically manage - as a means of influencing - "the perceptions of others" (Archer 2018:202). It thus picks up on Goffman's (1959) notion that performers (as he labelled them) deliberately adapt their behaviour as a means of making a certain impression on their audience and do so in ways that implicitly ask that audience to take their performance seriously. When seeking to understand the meaning of questions and answers, especially where deception (or evasion) is a possibility, this means considering not only whether (and, if so, how) the expectation and/ or outcome of deceptive or evasive responses is influencing and informing the questioners' strategies and question design, but also how the respondent seeks to deal with this. In Weiner's case, for example, IM proved to be an important means by which he sought to defend the (political) reputation he had built over several years against credibility damaging - and what proved to be career-destroying - allegations (see Hall 1972, for a discussion of political impression management). Huntley's projection of a "positive public image" (Goffman 1955:214), in contrast, had been crafted during a few brief television interviews he had given shortly after Holly and Jessica went missing (during which he admitted to being the last person to see them alive). His goal was nonetheless similar to Weiner's: that of maintaining "credibility in the eyes of others" (Gass and Seiter 2015:90). As Section 3 will highlight, Huntley sought to do this by providing the police officer with an answer she was likely anticipating at this point (i.e., no), but it was undermined by contradictory non-linguistic behaviours on his part.

We might note an additional fact about IM at this point, namely, that it is sometimes used with the aim of deceiving others. Indeed, a widely cited hypothesis holds that liars tend to "put more effort into making a convincing impression than truth tellers" (Vrij 2008:194). Deceptive IM can thus take various forms. Houston et al (2012) advise their readers to pay attention to an interlocutor's sudden or marked use of religious belief/values/character references, credibility labels and/or proof/evidence frames, for example. Archer and Lansley (2015:237-8) suggest paying attention, in addition, to interlocutors' attempts to represent others in ways that advantage self over those others. Politeness that seems "inappropriate" to - by being at odds with - the context may also prove significant, given that IM is "largely achieved using linguistic features" that include "(non)adherence to politeness and conversational rules” (Archer 2018:206, see also Holtgraves 2013). As Section 2 will highlight, the last two examples are both drawn upon by Weiner, such that he uses the honorific "sir" repeatedly at the point his interaction with a press interviewer grows increasingly hostile as a means of characterising that particular press interviewer as someone who was preventing him from continuing with the interview. Claims about detecting deception should never 
be based on two examples of one indicator, of course. My analyses in Sections 2 and 3 thus focus on specific linguistic content, body movements, facial expressions, gestures, voice quality, etc., that appear to have been triggered by a stimulus - such as a question - to the extent of clustering across the communication channels at that point or shortly thereafter (Houston et al. 2012, Archer and Lansley 2015). Behaviours that do not appear to match the participant's verbal account but, instead, point to inconsistencies within and/ or across these "communication channels" (as Archer and Lansley 2015 call them) are particularly prioritised. ${ }^{1}$ In Goffmanian terms, this is akin to paying as much attention to the messages that individuals give off (unwittingly) as we might their intended messages (Goffman 1959).

\section{Weiner press interview}

Congressman Anthony Weiner was forced to combat allegations of sexual inappropriacy when a twenty-one-year-old female student alleged he had sent her a sexually explicit photograph on Twitter (on May 27, 2011). Extract 1 captures the first 91 seconds of a 7-minute, 34-second interview given by Weiner (shown as W below) on May 31, 2011. The female interviewer, Dana Bash (shown as I1 below), worked then - as she does now - for the US cable news channel, CNN. The name of the male interviewer (shown as I2 below) is not known.

\section{Extract 1: All you have to do is say no to the question}

1 I1 you say that you were hacked which is potentially a crime so why haven't you asked the capitol police or any law enforcement to investigate it

that I have now been talking about for a couple of days (.) I'm not gonna allow it to decide what I talk about for the next week or the next two weeks (H.) erm and so I'm not gonna be giving anything more about that today I think I've been pretty responsive to you in the past-

-but but with respect you're here which we- which we appreciate but you're not answering the questions can you just say why you haven't ak- asked law enforcement to investigate what you are alleging is a [(.) crime

[you- you know Dana if I was giving a speech to forty five thousand people and someone in the back of the room threw a pie or yelled out an insult would I spend the next two hours responding to that [no I would get back (.)

5 I2 [this is- that-

6 W I would ge[t back [I would get back7 I2 [this is not that [situation -this is not that situ[ation

$8 \mathrm{~W}$ get [back- well why don’t you do- do you wanna do the briefin[g

9 I2 $\begin{gathered}{[\text { you- }} \\ \text { your- you said- }\end{gathered}$ [I would I would [you were hacked 


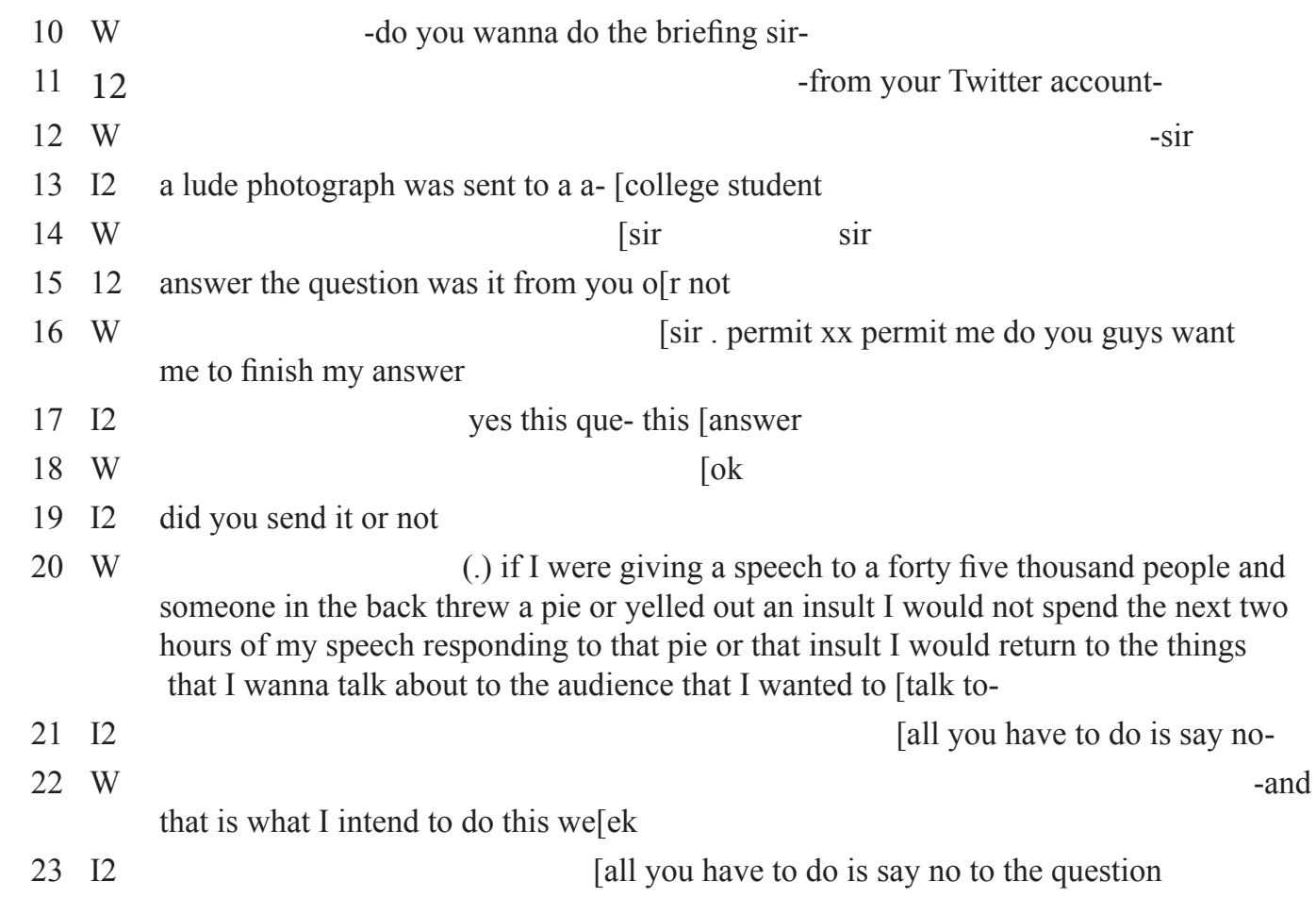

(Rep. Weiner Defends Handling of Photo Scandal, YouTube clip accessed 04/04/2019)

Bash's first utterance contained a why-interrogative (see turn 1) which, because it made use of negation, served to "indicate the speaker's expectation of and preference for" a specific answer (Archer 2005:26). It was made particularly conducive (and, hence, constituted a marked attempt by Bash to control Weiner) due to being part of a so construction, and being framed within a statement that,

(i) reported - in order to echo - Weiner's purported claim of being hacked (thereby potentially damning him with his own words) and

(ii) signalled the interviewer's own evaluation of that claim as a potential crime (against Weiner).

It thus fits Weinstein's (2001:107) criteria of a probing question, that is, a requirement that $\mathrm{X}$ - in this case, Weiner's failure to report the incident - "be further examined", but in such a way as to provide a satisfactory account (given Bash had effectively made this into an "issue"). Weiner's facial expressions, in particular, are thus worthy of note at this point. As Bash delivered her statement/ probing question, Weiner demonstrated lip, cheek and jaw movements that were indicative of an anger response, specifically, lip pressing, cheek blowing and jaw clenching (see, e.g., Lansley 2017). There was also an audible "tut" prior to Weiner providing an answer. We might label this type of linguistic feature a surge feature, following Taavitsainen (1999:219-220), given its association 
with "personal affect" and, in some cases, emotional outbursts. Weiner's linguistic response, immediately thereafter, suggests that - his surge feature apart - he was very much aware of, and engaged in, (deliberate) IM from this point onwards. The imperative, look, had a "performative nuance" (Ghezzi and Molinelli 2014:129); in the sense of demanding Bash pay attention to what he was about to say (see also Aijmer 2018). Rather than directly addressing her negatively structured why-interrogative, however, he introduced the idea that whatever had occurred was a prank. This particular turn thus shares some similarities with the defensive IM tactic of justification (Tedeshi and Melburg 1984) in that Weiner was endeavouring to explain (away) a negative circumstance. In this case, though, it was an attempt to trivialize what had occurred through carefully selected word choice(s) on the politician's part (cf. Bolino et al.'s 2008 definition of justifications as providing a reason or excuse for some negative action).

It is worth noting that responding without answering - by changing the textual content of the question - equates to a covert type of evasion; tantamount to concealing the fact that a cooperative answer has not been given (Galasiński 2000:62). There was evidence of additional evasive moves in this turn too (given what ultimately transpired). Weiner signalled (i) he had been responsive previously, for example, (ii) as well as providing evidence (from his perspective) that he was currently being harassed beyond what was reasonable by this point. In terms of his non-linguistic communication channels, Weiner repeatedly looked to the left and right (towards where Bash was standing) as he delivered his turn. He also shook his head (twice) when stating he was not gonna allow it to decide what he would talk about during the next week or next two weeks. There was a marked shoulder shrug, in addition, when he claimed he had been pretty responsive... in the past. For Western cultures, in particular, although shoulder shrugs can indicate resignation (and even powerlessness: see, e.g., Givens 2002), they are more commonly understood to signal "hesitation, uncertainty, doubt and[/or] lack of knowledge" (see, e.g., Jokinen and Allwood 2010:26). As such, we might be tempted to assume that Weiner had not been as responsive as he could have been (at this point), in spite of his protestations.

As utterance 3 of Extract 1 reveals, Bash initially responded with but but with respect you're here which we- which we appreciate but you're not answering the questions. Linguistic features such as with respect and appreciate prior to a contrastive conjunction, but, effectively equate to using overt linguistic politeness markers as a means of pre-empting - by varnishing a face-threatening accusation (see, e.g., Johnson and Clifford 2011) that, in this case, related to Weiner's evasiveness. Bash then went on to use an indirect request for information (can you just say) that pre-modified another (negatively-constructed) why-interrogative. Once again, then, Weiner was being invited to defend his position: albeit with increasing judgemental overtones from Bash (see Section 4). 
Weiner's linguistic response at this point was more equivocation. He referred to a hypothetical situation where he was giving a speech in a public context and someone threw a pie or yelled out an insult. The throwing of pies is not as odd as it might first appear, in a political context, given it can refer to protest that is designed to ridicule, embarrass and humiliate (Kuntzman 2005). The metaphor was accompanied by one manipulator (when Weiner touched his nose) and several (largish) arm illustrators ${ }^{2}$, all of which acted as a prelude to Weiner's rhetorical question: would I spend the next two hours responding to that (which he immediately answered) no (see turn 4 ).

At this point, Weiner was suddenly interrupted by I2 (the male reporter); and he seemed determined to emphasize that this [was] not that situation, given his repetition of this phrase (see, e.g., turns 5 and 7). The interruption instigated a pattern of face-threatening repetition from Weiner in return (see, e.g., turns 6 and 8), which he then exacerbated further by repeatedly asking (from turn 8) whether I2 wanted to do the briefing (increasing his volume as he did so).

Well why don't do- wha-do you want to do the briefing and do you want to do the briefing sir are examples, moreover, of a special type of rhetorical question - epiplexis - used “to reproach, rebuke, upbraid”, etc. (Zimmerman 2005:93). Such tactics are obviously face-threatening: in this case, having implications for both I2's negative face (his "want" to get the answers he needed rather than being impeded in his actions) and positive face (his "want" to be approved of and, hence, taken seriously as an interviewer).

As the above transcript reveals, the overlapping (which began noticeably from turn 4) also increased further at this point, allowing Weiner to frame I2 as preventing him from answering (thereby impacting on his own negative face). Such a move is in line with Archer and Lansley's (2015:237-8) deception-related tactic of representing others in ways that advantage self (see Section 1). Another of Weiner's tactics at this point - that of repeating sir (i.e., an overly polite term of address, given the conflictive exchange) as a type of request to be allowed to continue - constitutes an additional IM (as well as potentially deceptive) move on his part (ibid.). When the (staged) requests to continue failed, he then addressed all but I2, to ask whether those guys want[ed him] to finish [his] answer (see turn 14), thereby impacting upon the male interviewer's negative face. Although I 2 continued to respond too, Weiner ignored (most of) those responses and instead reiterated the hypothetical throwing pies scenario he had mentioned previously, prompting I2 to comment (somewhat frustratingly); all you have to do is say no to the question (see turn 12).

Turn 14 is interesting because it gives us a layman's perception of questions in this and, arguably, other settings too: namely, that questioners tend to ask questions on the assumption that their questions will get answers from their target (even if some constitute dispreferred responses, e.g., non-answers, refusals rather than acceptances, etc.). Some 14 turns later, Weiner made a 
related suggestion to the same interviewer (I2), albeit focussing on interviewer versus interviewee roles in this instance: why don't you- why don't you let me do the answers and you do the questions (turn 26). This adheres to the generally held belief highlighted in the Introduction to this paper: that "interviewers" tend to "restrict themselves to questioning and interviewees...to answering interviewer questions, or at least responding to them" (Clayman and Heritage 2002:97) in the main. It is worth noting, however, that their rationales for highlighting such (seemingly similar) perceptions were very different. Weiner was continuing to frame I2 as someone who was preventing him from responding. I2, in contrast, was insinuating that Weiner was being consistently and deliberately evasive: seemingly, because he had something to hide. Several days later it transpired that I2 (and other reporters) were right to be suspicious. As noted in the Introduction, Weiner admitted to sexting shortly thereafter, and has since served a prison sentence for additional sexting offences.

\section{Huntley police interview}

Ian Huntley was a caretaker at Soham Village College (in Cambridgeshire, England) when Holly Wells and Jessica Chapman went missing on $4^{\text {th }}$ August 2002. In a television interview, not long after, Huntley admitted he had spoken with the 10-year-olds on the Sunday they had disappeared, when he had been outside grooming his dog; and after they had spoken, had watched them walk away in the direction of the church. Huntley was first questioned by the police, in connection with the girls' disappearance, twelve days after their disappearance. His girlfriend, Maxine Carr, was also questioned. Both were released without charge at that time but then subsequently arrested in the early hours of $17^{\text {th }}$ August (on suspicion of murder). Extract 2 is a very short excerpt from one of Huntley's police interviews, where he was questioned by a female police officer (shown as PO, below). ${ }^{3}$

\section{Extract 2: Huntley police interview}

1 PO Throughout any of this Ian was there any occasion that you actually came into contact physical contact with the girls?

2 IH physical contact [no

3 PO $\quad[\mathrm{mm}$ ok

The police officer (henceforth PO) is not visible in the video. When seeking to make sense of this short clip, we are thus reliant on what she said and how she said it - as well as, importantly, how Huntley responded verbally and behaviourally. The first thing we might note, however, relates not to the example itself but to the activity type it represents (Levinson 1992). Namely, that the power asymmetry tends to be more marked in this activity type than it is in press interviews (even in coercive ones, such as Weiner's, where a discursive power struggle ensued: cf. Section 2). This said, it is possible for suspects to stay silent or answer with no comment within the UK. UK police 
officers can also downplay the typical, ritualized "question-answer routine" in order to make the activity feel "more like a conversation" (Shuy 1990:180) for the interviewee. This is especially the case when the PEACE interviewing model is being used, due to its emphasis on enhanced cognitive interviewing techniques (and, hence, the establishment of some level of rapport as an important first step of the interviewing process: see, e.g., Mulayim et al. 2014:39-40). We do not have sufficient detail to know how the PO dealt with her full interaction with Huntley, but - assuming her adherence to the PEACE model - Extract 2 (above) likely occurred as part of the third phase of interviewing, that is, at the point questions were being asked as a means of clarifying or potentially challenging the interviewee's account. ${ }^{4}$ Assuming the PO was familiar with a second, alternative (but complimentary) interviewing model - that of Conversation Management - she may have also been as interested in Huntley's nonverbal behaviours (ibid:41) as we are below.

Let's begin with the polar question the PO asked in turn 1, of Extract 2, which was pre-empted by an indirect reference to the girls' disappearance: throughout any of this. Huntley responded facially to this indirect reference using lip/mouth movements that included a lip lick indicative of a dry mouth, and muscular tension around the jawline (Lansley 2017). From this, the PO might have inferred a level of discomfort on Huntley's part. The PO followed her indirect reference to the girls' disappearance with a direct first-name address: Ian. Personal names in medial position, as here, effectively serve as attention getters (cf. Aijmer 2018): in this case, we might recognise it as a sort of "performative", aimed at directing Huntley's attention to the import of the PO's upcoming question (cf. Ghezzi and Molinelli 2014:129). When the PO went on to ask her polar question, it required Huntley to explain whether there was any occasion he had had physical contact with the 10-year-old girls.

A question such as this would have been stress inducing for Huntley, whether he was innocent or guilty of harming Holly and Jessica. What is potentially significant for our (multi-channel) analysis, then, is how he responded to the question, behaviourally, as it was being asked. He changed his position during the words that you actually came into contact, for example, suggesting thereby that he seemed to be anticipating the question might prove problematic for him. This was followed by him shuffling in his seat at the point the PO made clear by actual contact she meant physical (potentially, sexual) contact, and Huntley then leaning back in his seat, thereby adding weight to the interpretation that the question had, indeed, unsettled him.

When Huntley responded verbally to the PO's polar question, he did so by repeating part of her question - physical contact - before quickly answering no. Recapitulary echoing questions, as Quirk et al (1985:835-6) label them, repeat all or part of a message "as a way of having...content confirmed", but can also "have other functions", such as when they are used to express "incredulity" (see also Collin 2020, this issue, Mortensen 2020, this issue). An analysis based on the transcript alone potentially allows for either or both possibilities (i.e., 
a clarification/confirmation-seeking move and/or a signal of his incredulity at being asked such a question). Especially if we read the PO's self-correction from contact to physical contact as a means of introducing the topic of a new type of contact at this juncture based, importantly, on the knowledge that Huntley had previously admitted (in televised press interviews) he had talked with the girls (albeit after they first approached him to enquire about his girlfriend). Part of my argument for including facial and body movements as well as prosodic features, as part of such analyses, is that they can lead us to make very different interpretations of the meaning potential of questions and answers. In this case, for example, I would contend that Huntley's echo of part of the PO's previous turn was a means of giving himself some thinking time. My argument is based on a lack of prosodic features indicating incredulity, and Huntley not waiting for a verbal signal, from the PO, confirming her question centred on potential physical contact with the girls. Instead, his no overlapped with the PO's $\mathrm{mm}$. It remains possible that the PO used a head nod, which Huntley interpreted as confirmation, given she is not in shot herself; serving as a useful reminder that we should not base any interpretation - and assessments of deception especially - on any one behaviour (see Introduction). There are other potential indicators of deception that cluster at this point, though, such as Huntley answering a question with a question, and his volume decreasing on no, when compared with the echo question (Lansley 2017:49, Archer and Lansley 2015). Huntley's body language is significant at this point too. He anchored his hands, clasping them together in a way that (advertently or inadvertently) covered his genital area. Glass (2014) suggests such behaviour can indicate a person is feeling vulnerable or uneasy (possibly, due to a fear of being caught in a lie). Huntley gave off (Goffman 1959) two further, potentially revealing micro movements in addition: a single-sided shoulder shrug and a headshake that was out of sync with his uttering no. Significantly, for this analysis, both may be indicative of deception when they cluster with other deceptive indicators, as here (see, e.g., Lansley 2017:39). Goffman's argument that interlocutors communicate intentionally through the things they say, in conjunction with their facial expressions and other controlled body language, but also inadvertently give off impressions they did not specifically intend, is echoed by Schneider (1981), albeit using different terminology. Schneider labels the inferences people want others to draw from their self-presentation as calculated impressions, and those that are given off as secondary impressions. It is the latter, more difficult to control impressions that have "the capacity to alter the meaning of the calculated impression and in extreme cases...spoil it", according to Schneider (1981:33). It is likely that Huntley, for example, was seeking to persuade the PO that there had been no untoward physical contact between him, Holly and Jessica, but his body language, language choices and volume decrease suggested a very different reality that was ultimately confirmed at his court case (and resulted in his imprisonment). 


\section{The multiple factors from which questions glean their meaning-in- context: a summary}

This paper has demonstrated that the meaning-in-context of questions and answers is shaped by and/or interpretable using a number of interdependent, multi-channel factors, some of which appear to be ignored by researchers currently. The most commonly drawn upon factors tend to be a question's syntactic form and interactional force/function in context, of course. Less commonly discussed, perhaps, is a question's position within - in conjunction with what the questioner intends to achieve by - an exchange: possibly because the inclusion of a questioner's intentions takes us firmly into the territory of (socio)pragmatics (see, e.g., Archer 2005) and debates around whether it is possible to accurately retrieve speaker intention. As Grimshaw noted some 30 years ago, for example, what 'is in people's heads is accessible neither to analysts nor to interlocutors (nor even...to those whose behaviour is under investigation)' (1990:281). We are thus reliant, at best, on an assessment of plausible intentions, using the evidence available to us (whether we are participants of an interaction as it unfolds or analysing it post event for some reason, as here). Consider Extract 2, relating to Weiner (discussed, at length, in Section 2). Bash initially asked two questions of the then Congressman. The second question seemed to be necessary, from the interviewer's perspective, because Weiner had evaded (and, hence, not answered) the first. Evidence for such an interpretation includes both questions seeking the same information: why Weiner had not asked the capitol police or any law enforcement to investigate the malicious hacking of his Twitter account, given it was potentially a crime. Bash also used superficial politeness (see, e.g., but with respect you're here which we-which we appreciate) to varnish an otherwise, face-threatening accusation that Weiner was not answering the questions. It is partly because Bash repeated the same question in such close proximity to the first that she was able to frame Weiner as being deliberately evasive. Note, however, that Weiner was able to continue evading her question: in spite of the interviewer's use of an interrogative structure that is deemed to be highly conducive (Archer 2005). This particular interaction is thus a useful reminder that, although "certain question-types have the capacity to constrain...the addressee's response" (Archer 2005:54) by restricting what they might do (Wartenberg 1990), interlocutors like Weiner can still opt to respond such that they "avoid giving" the requested information (Archer 2005:60). Hence, the importance of studying not only the expectation of a response (verbal or otherwise) and interactional capacity to compel that response but also the responses that questions actually receive in context. It is only by so doing, in fact, that we allow "the answerer" (not just "the questioner") to have some "power over what happens next within a given encounter" (Sarangi 2010:236) and give due credence, thereby, to the notion of meaning being negotiated in context by all participants. We might note Sharrock's (1979:142) suggestion, for example, that the format of an answer "is in an answerer's control" to the extent of being 
constrained as much "by the answerer's sense of what the [best] answer is" as it is "by the form of the question" itself. This may be especially relevant in situations where questions can create credibility issues for respondents. It is for such reasons I also advocate paying attention to the potential use of IM by both the questioner (when asking his or her question/s) and the respondent (when answering them) in this paper. I have already noted Bash's implicature that Weiner was being evasive. The structure of Weiner's first response to Bash (see Turn 2 of Extract 1) seems to support such an interpretation, given Weiner changed the textual content of - as a means of avoiding having to answer - the interviewer's question (Galasiński 2000:62). Weiner seemed to want to appear cooperative, nonetheless: hence, presenting himself as a victim of $a$ prank, and as someone who, in spite of being responsive previously, was now being harassed beyond what was reasonable (see Section 2). His second response to Bash was also evasive - and arguably too evasive - given that Weiner employed a metaphor relating to throwing pies and a rhetorical question he was careful to answer himself, would I spend the next two hours responding to that no (Turn 4 ), which resulted in I2's (repeated) interruption of Weiner from that point onwards. As noted in Section 2, I2 was particularly at pains to emphasize that this was not that situation (see, e.g., Turns 5 and 7). As noted in the Introduction, questions that expect answers will always tend to impact upon a target's negative face (i.e., their "want" to act freely, without imposition) and can also affect the target's positive face in some contexts. Hence the importance of paying attention to interlocutors' face(work), as well as any attempts on their part to engage in IM, when seeking to understand questions and answers in context. For example, I2's continuous interruption(s) had implications for Weiner's negative face (because of impeding him from continuing) and his positive face (because of the growing insinuation that Weiner was being evasive not because he was fed up of answering something he had previously dealt with but because he had something to hide). At this point, Weiner became the questioner, repeatedly asking I2 (from Turn 8 of Extract 1) whether he wanted to do the briefing (increasing his volume as he did so). As mentioned previously (see Section 2), well why don't do- wha-do you want to do the briefing and do you want to do the briefing sir are examples of a special type of rhetorical question - epiplexis - used "to reproach, rebuke, upbraid", etc. (Zimmerman 2005:93). I have suggested such tactics were deliberately face threatening on Weiner's part: having implications for both I2's negative face (his "want" to get the answers he needed rather than being impeded in his actions) and positive face (his "want" to be taken seriously as an interviewer). In terms of IM, Weiner seemed to be seeking to frame I2 as preventing him from answering, even going as far as lamenting, via a negative whyinterrogative, that he should let him do the answers whilst he do the questions (turn 26). I2, in contrast, sought to frame Weiner as being inappropriately evasive: hence comments such as all you have to do is say no to the question (see turn 12). It is worth reiterating, here, too, that Weiner's IM, when viewed 
in conjunction with telling facial expressions and body movements, was ultimately indicative of deception on his part. Simply put, he - like Huntley gave off (Goffman 1951) impressions that served to contradict what he said when responding to questions (which included asking questions of his own). Yet, previous analyses of questions and answers have tended to exclude facial expressions and body movements from their analyses - even when they would be enriched by their inclusion. As this Section has discussed Weiner at length, thus far, let's focus on Huntley at this juncture. I noted, in Section 3, that Huntley gave off several facial and body movements at the point the PO asked her question about his physical contact with Holly and Jessica. There were also give-away signs (verbal and nonverbal) when he echoed physical contact, thereby answering a question with a question, before answering no (overlapping with the PO's $\mathrm{mm}$ as he did so). His volume was lower, with regard to the latter, than it was when asking physical contact, for example. He also gave off (Goffman 1959) a single-sided micro shoulder shrug and a micro headshake, which was out of sync with the no response. All of which served to contradict his denial of having had physical contact: and thereby suggested that he had (which ultimately proved to be the case). This paper contends that it is seemingly insignificant secondary impressions, such as this, that have "the capacity to alter the meaning" of a calculated impression, to use Schneider's term, "and in extreme cases to spoil it" (cf. Schneider 1981:33). I suggested in Section 3, for example, that Huntley was probably seeking to persuade the PO there had been no physical contact between him and the girls. When certain types of behaviour "suggestive of inconsistency" cluster across the communication channels "within a seven-second window", however, they may indicate that the truth is very different (see, e.g., Archer and Lansley 2015:232-3, 236). ${ }^{5}$

\section{Concluding comment}

This paper has sought to demonstrate not only that questions are communicative acts of elicitation, whose meaning-in-context is shaped by and/or interpretable using a number of interdependent, multi-channel factors, but that multi-channel approaches can also help researchers better account for the impressions interlocutors like Weiner and Huntley give off (Goffman 1951) when asking and responding to questions. This includes having the potential to help us detect deception: especially when inconsistencies are triggered by a stimulus - such as a question - and cluster across the communication channels at that point or shortly thereafter (i.e., within a seven second window of a stimulus). Researchers interested in explaining the characteristics of questions for the purposes of a grammar textbook, for example, may not want to include all the multi-channel factors that this paper argues (help to) shape questions (and the answers they glean) in their context-of-use. I say this as the type of analysis advocated by this paper will have to focus as much on what a questioner means when asking $\mathrm{X}$ as they do on the formal structure of a 
given question or (set of) questions. An interest in what the questioner means is paramount for anyone interested in meaning-in-context, however. I would argue that so, too, is paying equal attention to the message(s) a questioner and their respondent(s) may be giving off, albeit unwittingly (cf. Goffman 1959), as they interact together. As this paper has shown, this means paying attention to a participant's facial expressions, body movements and gestures when asking and/or responding to questions, as well as their face(work) and their use of IM (including instances where they might be using IM for deceptive purposes). It remains the case, of course, that what is in people's heads is accessible neither to analysts nor to interlocutors (nor even...to those whose behaviour is under investigation)' (Grimshaw 1990:281). As such, we must use the best evidence available to us (whether we are engaged in an interaction as it unfolds or researchers analysing it post event) in order to assess the most plausible intentions of those involved. I would contend that the kind of approach advocated here encourages us to use more of the evidence available to us - by insisting we pay attention to all communication channels rather than prioritising (certain aspects of) language only.

\section{Notes}

1 This multi-channel approach has been devised by the EIA Group, and is based on 27 research-validated criteria tested in diverse fields (i.e., intelligence services, law enforcement, fraud investigation, etc.: see Archer and Lansley 2015).

2 Friesen et al. (1980) introduced the terms, manipulator and illustrator, as part of their three-part coding system for classifying hand movements (alongside emblem). As Bull (1989:159) notes, manipulators "satisfy self or bodily needs", and can range from self-soothing/stroking behaviour through scratching an itch to manipulating an object (by, e.g., tapping a pen on a desk). Illustrators, in contrast, "follow the rhythm and content of speech, and typically do not involve contact with an object or part of the body" (ibid.).

3 The clip was made available to the author for analysis as part of the Investigation Discovery series, Faking It: Tears of a Crime (see Series 2, Episode 1).

4 After establishing some level of rapport and explaining the aims of the interview, a police officer will invite their interviewee to provide a (free) account, in relation to the matter under investigation, during the first phase of the interview. In the second phase, areas of investigative interest (including topics not raised by the interviewee) will be developed/covered in more depth thereby setting up the third phase (i.e., the asking of questions designed to clarify or challenge the interviewee's free account).

5 The argument for paying "especially close attention to [a] person's cross-channel behaviour immediately after a prompt for question (i.e., up to seven seconds)" (Archer and Lansley 2015:232) is based on an understanding of being able to "reasonably conclude...the behaviour is directly associated with the stimulus" (Houston et al. 2012:30). 


\section{References}

Aijmer, Karin. 2018. Positioning of self in interaction: Adolescents' use of attention-getters. K. Beeching, C. Ghezzi and P. Molinelli (eds.) Positioning the Self and Others : Linguistic Perspectives. Amsterdam and Philadelphia: John Benjamins, 177-196.

Archer, Dawn. 2018. Negotiating difference in political contexts: An exploration of Hansard. A. Haselow (ed.) Dialogism and language change. Special issue of Language Sciences 68, 22-41. Online (accessed 10 Jan 2018): https://doi.org/10.1016/j. langsci.2017.12.005.

Archer, Dawn. 2005. Questions and Answers in the English Courtroom (1640-1760): A Sociopragmatic Analysis. Pragmatics and Beyond New Series. Amsterdam/ Philadelphia: John Benjamins.

Archer, Dawn and Cliff Lansley. 2015. Public appeals, news interviews and crocodile tears: An argument for a multi-channel annotation scheme. Corpora 10(2), 231258.

Bolino, Mark C., K. Michelle Kacmar, William H. Turnley and J. Bruce Gilstrap. 2008. A Multilevel Review of Impression Management Motives and Behaviors. Journal of Management 34(6), 1080-1109.

Brown, Penelope and Stephen C. Levinson. 1987. Politeness: Some Universals in Language Usage. Cambridge: Cambridge University Press.

Bull, Peter 1989. Psychological Approaches to Transcription. D. Roger and Peter Bull (eds.) Conversation: An Interdisciplinary Perspective. Clevedon, Philadelphia: Multilingual Matters, 150-165.

CBS. 2011. Weiner Admits Tweeting Lewd Photo \& Having Multiple 'Inappropriate' Online Relationships. Online (accessed 4 April 2019): https://newyork.cbslocal. com/2011/06/06/shirtless-photos-allegedly-of-anthony-weiner-posted-on-biggovernment-com/.

Clayman, Stephen and John Heritage. 2002. The News Interview : Journalists and Public Figures on the Air. Cambridge: Cambridge University Press.

Collin, Winnie 2020, this issue. "It was probably that guy?" - The functions of reconstructive speech acts in investigative training interviews. Scandinavian Studies in Language 11(1), 170-195.

Friesen, Wallace V., Paul Ekman and Harald Wallbott. 1980. Measuring hand movements. Journal of Nonverbal Behaviour 4, 97-113.

Galasiński, Dariusz. 2000. The Language of Deception: A Discourse Analytical Study. London: Sage Publications.

Gass, Robert H. and John S. Seiter. 2015. Persuasion: Social Influence and Compliance Gaining. (Fifth Edition). London and New York: Routledge.

Ghezzi, Chiarra and Piera Molinelli. 2014. Italian guarda, prego, dai. Pragmatic Markers and the Left and Right Periphery. K. Beeching and U Detes (eds.) Discourse Functions in the Left and Right Periphery: Crosslinguistic Investigations of Language Use and Language Change. Leiden: Brill, 117-150. 
Givens, David B. 2002. The Non-Verbal Dictionary of Gestures, Signs \& Body Language Cues. Spokane, Washington: Center for Nonverbal Studies Press.

Glass, Lillian. 2014. The Body Language of Liars: From Little White Lies to Pathological Deception: How to See through the Fibs, Frauds and Falsehoods People Tell you Every Day. Canada: The Career Press.

Goffman, Erving. 1967. Interaction Ritual: Essays in Face-to-Face Behavior. Chicago: Aldine.

Goffman, Erving. 1959. The Presentation of Self in Everyday Life. Arden Ci: New York. Grimshaw, Allen. 1990. Research on conflict talk: Antecedents, resources, finding, directions. A.D. Grimshaw (ed.) Conflict Talk : Sociolinguistic Investigations of Arguments and Conversations. Cambridge: Cambridge University Press, 281-324.

Hall, Peter. 1972. A Symbolic Interactionist Analysis of Politics. Sociological Inquiry 42(3-4), 35-75.

Haworth, Kate. 2006. The dynamics of power and resistance in police interview discourse. Discourse \& Society 17(6), 739-759.

Holtgraves, Thomas M. 2013. Language as Social Action : Social Psychology and Language Use. New Jersey and London: Lawrence Erlbaum Associates.

Houston, Philip, Michael Floyd and Susan Carnicero. 2012. Spy the Lie. New York: St Martin's Press.

Johnson, Alison and Ruth Clifford. 2011. Polite incivility in defensive attack: Strategic politeness and impoliteness in cross-examination in the David Irving vs. Penguin Books Ltd and Deborah Lipstadt trial. Journal of Politeness Research: Language, Behaviour, Culture 7(1), 43-71.

Jokinen, Kristina and Jens Allwood. 2010. Hesitation in Intercultural Communication: Some Observations on Interpreting Shoulder Shrugging. Proceedings of the International Workshop on Agents in Cultural Context, The First International Conference on Culture and Computing. Kyoto: Japan, 25-37.

Konzett, Carmen. 2012. Any Questions? : Identity Construction in Academic Conference Discussions. Boston/Berlin: Walter de Gruyter.

Kuntzman, Gersh. Pie-Faced: Why throwing a pie at someone who deserves it is one of the most celebrated traditions in our so-called culture. Newsweek, April 182005. (Accessed 12/04/2019).

Lansley, Cliff. 2017. Getting to the Truth: The practical, scientific approach to behaviour analysis for professionals. Manchester: EIA Group.

Levinson, Stephen C. 1992. Activity types and language. Paul Drew and John Heritage (eds.) Talk at Work: Interaction in Institutional Settings. Cambridge: Cambridge University Press, 66-100.

McKinlay, Andrew and Chris McVittie. 2009. Social Psychology and Discourse. Oxford: John Wiley \& Sons.

Mortensen, Sune S. 2020, this issue. A question of control? Forms and functions of courtroom questioning in two different adversarial trial systems. Scandinavian Studies in Language 11(1), 239-278. 
Penman, Robyn. 1994. Facework in communication: Conceptual and moral challenges. Stella Ting-Toomey (ed.) The Challenge of Facework: Cross-cultural and Interpersonal Issues. Albany, NY: State University of New York Press, 15-45.

Quirk, Randolph, Sidney Greenbaum, Geoffrey Leech and Jan Svartvik. 1985. A Comprehensive Grammar of the English Language. London: Longman.

Rep. Weiner Defends Handling of Photo Scandal. YouTube clip. Online (accessed 4 April 2019): https://www.youtube.com/watch?v=05-_LIOd5nM.

Sarangi, Srikant. 2010. The Spatial and Temporal Dimensions of Reflective Questions in Genetic Counselling. Alice Freed and Susan Ehrlich (eds.) Why Do You Ask? : The Function of Questions in Institutional Discourse. Oxford: Oxford University Press, 235-255.

Schneider, David J. 1981. Tactical self-presentations : Toward a broader conception. James T. Tedeschi (ed.) Impression Management Theory and Social Psychological Research. New York: Academic Press, 23-40.

Sharrock, Wes. 1979. Portraying the professional relationship. Digby C. Anderson (ed.) Health Education in Practice. London: Croom Helm, 125-146.

Shuy, Roger W. 1990. The Language of Confession, Interrogation, and Deception. Thousand Oaks, London: Sae.

Taavitsainen, Irma. 1999. Personality and style of affect in the Canterbury Tales. Geoffrey Lester (ed.) Chaucer in Perspective: Middle English Essays in Honour of Norman Blake. Sheffield: Sheffield Academic Press, 218-234.

Tedeshi, James T. and Valerie Melburg. 1984. Impression Management and Influence in the Organization. Samuel B. Bacharach and Edward J. Lawler (eds.) Research in the Sociology of Organizations. Greenwich, Connecticut: JAI, 31-58.

Vrij, Aldert. 2008. Detecting Lies and Deceit : Psychology of Lying and its Implications for Professional Practice. Second edition. Chichester: Wiley.

Wartenberg, Thomas E. 1990. The Forms of Power : From Domination to Transformation. Philadelphia: Temple University Press.

Weinstein, Rebecca J. 2001. Mediation in the Workplace : A Guide for Training, Practice, and Administration. London: Greenwood Publishing Group.

Zimmerman, Brett. 2005. Edgar Allan Poe : Rhetoric and Style. Montreal: McGill Queen's University Press. 